Rowlinson, S., 2019. Development of a roadmap for occupational health, safety and wellbeing in the Hong Kong construction industry: An institutional analysis. In: Sandanayake, Y.G., Gunatilake, S. and Waidyasekara, A. (eds). Proceedings of the $8^{\text {th }}$ World Construction Symposium, Colombo, Sri Lanka, 8-10 November 2019, pp. 276-285. DOI: doi.org/10.31705/WCS.2019.28. Available at: https://2019.ciobwcs.com/papers

\title{
DEVELOPMENT OF A ROADMAP FOR OCCUPATIONAL HEALTH, SAFETY AND WELLBEING IN THE HONG KONG CONSTRUCTION INDUSTRY: AN INSTITUTIONAL ANALYSIS
}

\author{
Steve Rowlinson ${ }^{1}$
}

\begin{abstract}
The industrial accident rate in Hong Kong has steadily declined over the past 20 years, but has plateaned over the past 5 years and worryingly the fatality rate has been flat for over 15 years. This clearly highlights a level of under reporting of accidents in that normally accidents and fatalities are in a roughly constant proportion to one another. This is corroborated by informal discussions with the insurance industry. Using an institutional analysis approach to the study, the research team has drawn the conclusion that institutional, contractual and policy factors adversely affect Hong Kong's OHSW statistics. This paper highlights the fact that many of these factors are not under Hong Kong contractor's control. However, there is always opportunity to improve performance and a series of potential initiatives are proposed that target industry-wide issues. An overarching issue for a company is the balance between the systems it operates and the culture within which it operates. A key issue in project-based organisations is to operate with rigid flexibility throughout the business. The goal is rigid conformance to safety standards but flexibility in how these standards are achieved. This characteristic is typical of high reliability organisations.
\end{abstract}

Keywords: Construction Industry OHSW Roadmap; Hong Kong Contractor; Institutional Analysis; Policy; Safety Leadership.

\section{THE CONTEXT}

The industrial accident rate in Hong Kong has steadily declined over the past 20 years, but has plateaued in recent years with no noticeable improvement over the past 5 years. Much of the improvement has been in the public sector with the private sector obviously lagging far behind. More worryingly, the fatality rate has been flat for over 15 years. This clearly highlights a level of under reporting of accidents in that accidents and fatalities are in a roughly constant proportion to one another. These trends and issues have been corroborated by informal discussions with the insurance industry. The research presented here was undertaken in collaboration with a major Hong Kong contractor through interviews and observations on site and in head office. A whole range of personnel were interviewed from directors through project managers, supervisors and workers in order to

\footnotetext{
${ }^{1}$ Department of Real Estate \& Construction, The University of Hong Kong, Hong Kong, steverowlinson@hku.hk
} 
deliver a balanced picture of the current state of the industry. A 360 degree safety climate survey was conducted to validate findings and this will be reported in due course

This study has three objectives:

1. To explain why there is continuing poor Occupational Health \& Safety and Wellbeing (OHSW) performance in Hong Kong despite a range of initiatives

(Note: This paper does not address the wellbeing issues due to space limitations);

2. To describe the context (and reasons) for the poor performance;

3. To make recommendations for change in the Hong Kong industry.

Generally, different projects exhibit their own safety culture and climate but have the same objectives for OHSW performance. However, to achieve these objectives project directors place different emphases on particular aspects of the safety management system and they do employ different operating procedures. This seems to be an appropriate reaction to the differing institutional backgrounds in which they operate. An overarching principle is the balance between the system and the culture within which it operates. A key issue in project-based organisations is to operate with rigid flexibility throughout the business. That is to be flexible in the way one goes about achieving goals but rigid in the standards that one sets for these goals. This is a difficult task as it is based essentially on people and their competence and their attitudes to implementing standards, essentially a behavioural approach from top to bottom in the organisation. Hence, this is much more difficult than introducing the same safety management system across the whole of the business in that it entails a sophisticated and mature safety management system, which takes into account different cultures, different ecologies and different demographics.

Hence, the systems will not be identical as they operate in different cultures. Typically, Singapore is a highly structured society; The Philippines is somewhat chaotic but exhibits a high power distance; workers in Malaysia may be considered as laid back as they may in Indonesia but Indonesia has a strong, clan culture; Hong Kong is considered to be the leader in construction management because of its "can-do attitude" but its workers are regarded by managers as risk takers.

Thus, any new initiatives must be based upon an understanding of these different cultures and the institutions that govern society. Also, demography, age, education and discipline of the workforce, must be taken into account in implementing standards and incentives to work safely must fit within these differing contexts. There is no one size fits all approach to improving OHSW performance.

The approach to accident prevention and safety enhancement in Hong Kong needs serious, fundamental change. Current poster campaigns and safety initiatives pay lip service to the need to improve safety through leadership and management of the whole design and construction process. We see a visible presence of safety propaganda but no tangible improvements in performance.

There is a widely held view in Hong Kong that safety on site is purely the contractor's responsibility. That is not the case. It is accepted worldwide that responsibility for safety lies with the client first and foremost and through client leadership becomes a joint responsibility of the whole project team (Lingard et al., 2009 and Sherratt, 2014).

Now is not the time for tinkering with a range of minor initiatives; the problem is urgent, as evidenced by the number of fatalities over the past 10 years averaging over 23 per annum and showing no significant downward trend (Hong Kong Housing Authority, 
2019). Fundamentally the problem lies with Safety Leadership. Major clients in the industry must drive change in order to enable Safety in Design to be properly implemented in all projects. This requires truly collaborative working and establishing health and safety as the top priority in design, construction, maintenance and use of new facilities.

\section{ISSUES ADDRESSED IN THE STUDY}

This research was based on one contractor that operates in Hong Kong but also has projects in other parts of South East Asia. The overarching objective was to assess how and why performance in Hong Kong differed from performance in other parts of the region - the Hong Kong malaise.

\subsection{ISSUE 1}

When a business works on different projects in different countries, there is a difference in safety management maturity in each project. This comes about because the institutional context in each country is different and projects operate under different:

- legislation and codes of practice,

- professions with different governance,

- expectations, norms and values,

- processes and routines,

- levels of training, competence and degree of specialisation, and

- cultural differences (of all kinds).

Thus standards, expectations and practices are inevitably different. The differences cannot be readily controlled by any of the individual projects (nor any other multinational organization).

This context creates a barrier to the effective transfer of good practice across projects. This is normal and to be expected. Thus, because of the breadth of geography, institutions and cultures across regional projects, each will exhibit its own unique level of safety management maturity. This range of maturity also applies to different sites within the same country. The goal of a mature business should be to create a high reliability organisation (Koh et al, 2013) that is resilient and can achieve "best in class" performance in all contexts. This is the challenge facing the Hong Kong based contractor.

\subsection{ISSUE 2}

Change cannot be brought about without a clear understanding of context. This study sprang from the fact that the safety metrics in Hong Kong appear to have plateaued. In Hong Kong, institutional issues work against effective management of OHSW. Governance of the industry, client attitudes and expectations, the tendering and bidding system, extensive sub-contracting and the use of piece-rate payment systems, and the role and goals of organisations such as the Labour Department create an unreceptive environment for OHSW improvement. Furthermore, there is an inherent lack of safety leadership at this institutional level. Overseas projects operate in a context that is in many ways more benign than that in Hong Kong. The contexts may not be as sophisticated as Hong Kong but they can be more conducive to control of OHSW in these business units. 


\subsection{ISSUE 3}

The following discussion addresses the institutional context first and foremost. Without change in the context and the exercise of leadership at the institutional level initiatives at project level will never be fully effective. The Hong Kong industry context is addressed first, then the project context.

\section{A CONSTRUCTION INDUSTRY ROADMAP FOR CHANGE IN HONG KONG}

The time is ripe for a fundamental change in the way that the industry conducts its business, starting with the tendering and bidding system by incorporating provisions for adequate time to incorporate safety into design. The ageing workforce lacks competence in certain key skills and is in short supply. Thus, demand must be matched with labour supply otherwise new safety initiatives will be futile. Subcontracting needs to be governed at this institutional level by an accreditation system that rewards safe performance, not lowest price. The governance structures of the industry must change and more use made of relational contracts to enable collaborative design and construction, including early contractor involvement. Client leadership is essential in order to drive this change and refresh the industry's approaches and attitudes. This task cannot be achieved by an individual contractor; it has to be a collective push for change.

\subsection{INDUSTRY ROADMAP FOR AN INCIDENT FREE ENVIRONMENT}

The Hong Kong construction industry is in urgent need of a vision for the future that is incident free. In order to achieve this, we need visible leadership and a roadmap to direct the industry to this objective. There are a number of key elements missing in the way construction is undertaken in Hong Kong that make it very difficult for individual contractors to improve safety and health performance. Individual contractors' initiatives are thwarted by the inertia of the institutional context in which they operate. This context must be changed and directed by an industry roadmap for an incident free environment which must address the following issues:

There is no driving mechanism for Safety in Design. Clients demand neither a design management coordinator nor a design risk register and construction design management for safety is not mandated;

The bidding system leads to risk taking by the bidder and price cutting and the workforce feels the pressure of this risk-taking;

Consequently, safety management on site has become a firefighting exercise, it is reactive rather than proactive;

Safety starts with design but at top levels within organisations there is a lack of comprehension and understanding of how OHSW works. Particularly, major clients and consultants do not recognise the health and safety problems in the same way that contractors and workers do;

There is little incentive to self-manage projects. The maintenance of a direct labour force is not economically viable for contractors in this competitive market. The use of piece rate payment systems leads to risk taking by construction workers; 
There is a reluctance to prosecute workers for obvious breaches of legislation and inhouse safety rules. This lack of sanction fuels the risk-taking propensity of some construction workers;

Hong Kong as a whole exhibits the cultural trait of "Eastern Pragmatism", which involves adapting behaviour to situation, context and time. Thus, an attitude exists where rules are there to be broken and practices change to suit the individual. This goes against many of the tenets of effective safety management practice.

At the strategic level of the industry, there is a lack of vision and leadership. The mechanisms that are used to procure construction are outdated and adversarial. There is a distinct lack of collaboration across the industry and institutionalised barriers exist to learning and informing on ways to design safety into projects. BIM is not being used to its full potential in this respect and this is mainly because we have neither Integrated Project Delivery (IPD) nor Early Contractor Involvement (ECI) (Lingard et al, 2014). This situation points to the need to move towards collaborative and relational procurement, in the whole supply chain. This requires adoption of modern forms of construction contract, such as NEC, and a more rational approach to bidding is required. Only then will Safety in Design be achievable. Today, there is an urgent need to manage the demand generated by the industry so as to match the supply capacity: this means projects must be brought to the market more slowly.

At this institutional level, what is required is an industry roadmap that maps out a route to industry change that will in turn cascade down to the company and project level. This will stimulate change in attitudes and working practices, build competences and lead to a safer and healthier industry. A strategic level roadmap is presented below in Figure 1. Initiatives that can be undertaken by the contractor are expanded upon below.

\section{THEORETICAL BASIS FOR THE STUDY}

This study has taken a theoretically based, institutional analysis approach in order to provide a credible academic basis for the propositions put forward in this study and to provide a framework in which the "real" situation can be explored in the interviews and site visits

Institutional issues include different cultural values within the domains of government, workers and clients and different expectations, requirements and industry governance. These are mainly things that are outside of the control of the contractor in that they are inherent to the worker and his culture or are products of the economic, political and social climate of the location. These are, in the main, beyond the immediate, short-term control and influence of the contractor and have to be dealt with as such.

Contractual issues relate to bidding, employment, payment, employee's compensation insurance and other factors and are under the control of the contractor in some way but not entirely so;

Policy issues reflect the attitude of legislators, government and other stakeholders and are not under the control of the contractor but the contractor may well influence these issues, in the longer term rather more often than immediately. Issues such as labour importation, OHSW training and inspection regimes come under this category. In Hong Kong, bodies such as the OSHC and CIC that provide training for industry improvement and over, 
which the contractor has no control are relevant here. These have the potential to impact negatively on OHSW management in Hong Kong;

Internalisation refers to the ability of the contractor to internalize, specify and manage certain functions, such as training, and so drive performance above the norm of the industry as a whole. As far as OHSW training, education and management goes Hong Kong contractors score highly on these aspects.

The basis of this study, in layman's terms, focuses on the high level of incident reporting as not necessarily reflecting poor safety management but as a result of institutional and policy issues which are not under individual contractor' control. These are bigger industry issues that will take time to resolve. Examples of how this can happen are the BuildSafe initiative in USA (a private sector driven initiative, see Metropolis Group Inc., 2019) and the management of OHSW for the London Olympics infrastructure (a public sector driven initiative, Olympic Delivery Authority (ODA), see Engineering News Record, 2019). At present, there is no institutional and policy drive to approach OHSW in this way in Hong Kong. Obvious champions for change and key institutional players in this respect are the Construction Industry Council (CIC), the Occupational Safety and Health Council (OSHC) and the government's Labour Department. There are opportunities to improve OHSW performance in Hong Kong but the major barriers to improvement in Hong Kong are institutional and policy issues; overcoming these will require long term planning and adjustment by all parties and changes in culture in client organisations and government bodies

\section{WHY DO WE NEED A ROADMAP?}

Effective safety management lies in a complex series of processes that must be implemented in order to deal with safety issues in a whole range of situations that may arise within an industry or on a particular site. If we are to keep our industry and our sites safe, we need a roadmap that will lead to institutional and organisational maturity in the construction industry. The roadmap needs to be generic so that it can be applied in different cultures and at different stages of development. Thus, what is proposed here is a safety roadmap for the Hong Kong construction industry.

When a company works on numerous different projects at any point in time there is inevitably a variability of safety maturity in each project that creates a barrier to the effective transfer of good practice across the organisation. This is normal and to be expected. If one accepts this premise that because of the breadth of distance, institutions and cultures across projects, each will exhibit its own unique level of safety maturity. It is already accepted within the contractor management that traditional quantitative measures of safety performance, lag measures, only determine the level of past performance but provide little insight into strategies that may be successful or are transferable amongst other projects. The traditional lag indicators give no insights into prevailing values, behaviours and beliefs in the construction industry. Thus, if it is recognised that effective safety performance is predicated upon both qualitative and quantitative data assimilation and analysis, then it is necessary to provide a framework that is common across the whole organisation that can be used to guide and direct safety measures. A safety roadmap provides this framework and indicates both destination and waypoints on the way that need to be followed in order to reach this final destination. 
The roadmap construct applies both to organisations and to industries. The Hong Kong construction industry, through the CIC, needs to develop its own Road Map in order to reach this, perhaps not articulated by CIC as yet, destination. Zero fatalities should be a target destination in the first instance.

\section{WHAT ARE THE PRINCIPLES BEHIND THE ROADMAP?}

Section 3 clearly lays out the issues identified as contributing to poor OHSW performance in Hong Kong. The aim of the roadmap should be to address the issues raised above. Thus, along with the roadmap there has to be a system whereby contractors, subcontractors and designers are certified in terms of their safety performance. This system must differentiate between good and bad performers in terms of OHSW and the administering body have powers to remove certification. An overarching principle should be a focus on discouraging piece rate payment systems.

There needs to be a change of approach amongst the institutional players who must become more proactive in the way they address prosecutions and industry engagement. CIC's Construction Industry Performance Report lists three OHSW KPIs, the third of which is "Number of summonses convicted per HK\$100m gross value of construction works". Such a KPI sends completely the wrong message to the industry. Indeed, key performance indicators should include a reduction in prosecutions and an improvement in the industry's accident statistics. A key set of metrics should include:

- Reduction in incident rate annually;

- Reduction in fatality rate annually;

- Reduction in the number of contractor prosecutions;

- Appropriate level of worker prosecutions;

- Increased competence in and engagement with the key players.

At this institutional level what is required is an industry roadmap that maps out a route to industry change that will in turn cascade down to the company and project level. This will stimulate change in attitudes and working practices, build competences and lead to a safer and healthier industry.

\section{INSTITUTIONAL MATURITY}

The purpose of the roadmap is to provide a framework for assessing the development of institutional maturity. This is necessary in order to ensure that the industry is heading on the right route to its ultimate destination that is zero fatalities and an incident free environment.

The roadmap helps on the journey already started to move from a static industry adopting $a d-h o c$ responses and initiatives to one with a sense of direction and purpose. The roadmap allows for a combination of qualitative and quantitative assessment with a series of metrics that are suitable for the journey. Underlying the roadmap is the sense of being able to feel how good safety is. The roadmap also recognises different businesses, different construction sites, different subcontractors and different project managers, as well as different stages in projects, all lead to the need to follow a route that leads to the same outcome but may pass different waypoints. However, all routes lead to the same destination: incident free construction. The roadmap is presented in Figure 1. 


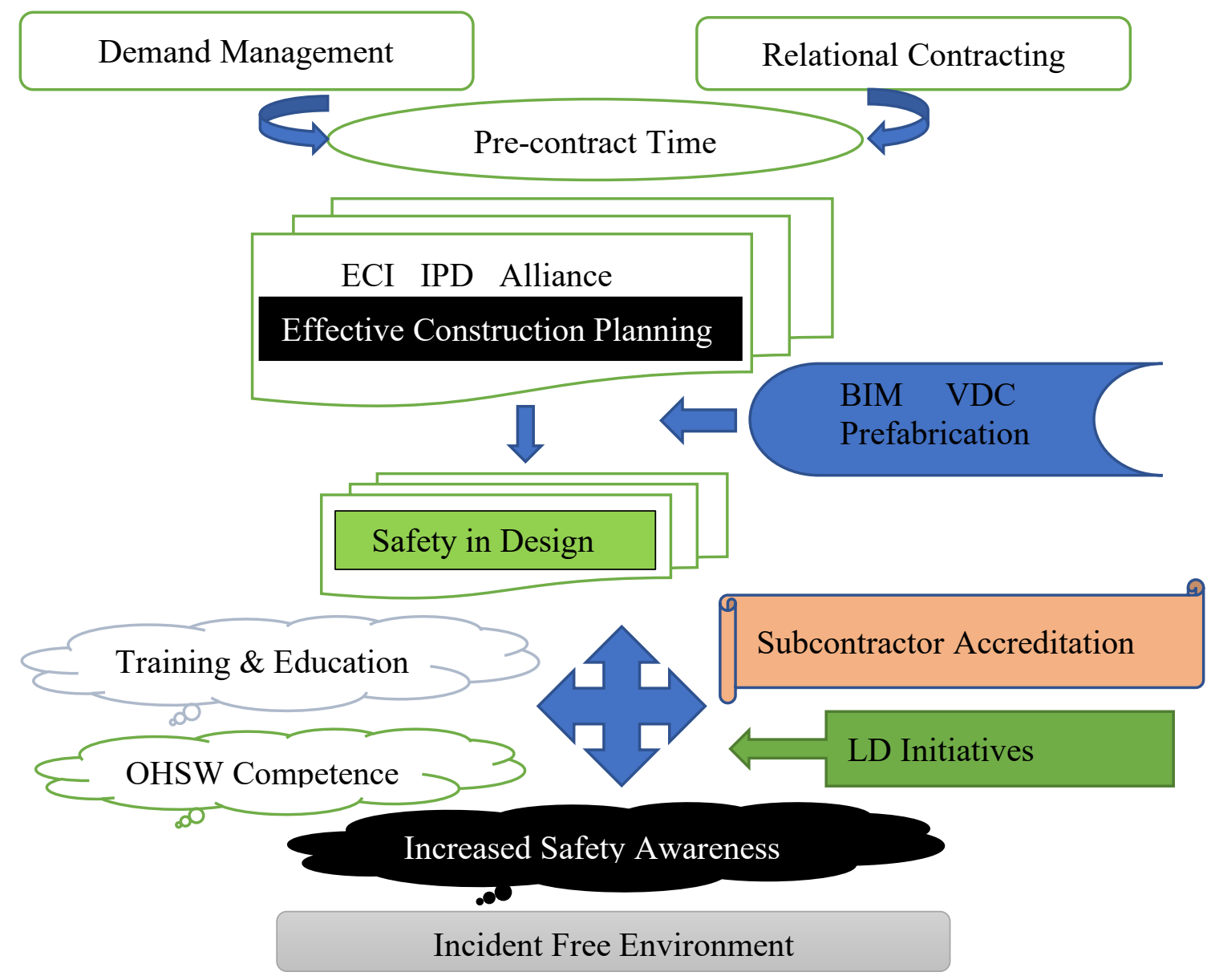

Figure 1: Hong Kong construction industry safety roadmap

\section{THE WAY FORWARD}

\subsection{Tendering AND BIDDING}

The tendering and bidding process must be reviewed in order to allow time and resources to plan for safety effectively and to fairly assess contractors' safety records. Projects spend an enormous amount of time in the planning and outline design phase and then are rushed into the bidding and award process with infeasibly short construction periods being specified. This allows no proper time for value engineering, programme planning, method statements and risk analysis. These tasks should take place concurrently with design and there is evidence from USA, Australia and UK that early contractor involvement, collaborative contracting and virtual design and construction all contribute to safety improvements. These trends are pushing the industry in developed countries to proper IPD (integrated project delivery) which achieves time, budget quality and safety and health goals. Integrated teams provide solutions which are innovative and which individual teams on their own would not come up with.

\subsection{EARLY CONTRACTOR INVOLVEMENT}

By making early appointments of key players in a project, we achieve more effective planning, coordination and cooperation that addresses commercial and health and safety issues and provides an integrated approach to risk management where health and safety, 
technical, financial, time and environmental risks can all be addressed and balanced in an open forum. In the long term, this will raise the competence of designers in respect of safety and health. The motto adopted in London 2012 was "only build things once" and this reflected the vision of the leadership of the integrated team and its focus on safety first. This would allow for a very specific focus on safety and health in bid assessments.

\subsection{Policy Change}

Overarching this structural change, there needs to be a policy change in that output of the industry needs to be managed in order to match the labour force constraints that Hong Kong has at the moment. By stretching industry capacity, safety and health suffer. The same applies to the pace of construction: Hong Kong Housing Authority slowed the pace of construction of their products in the late 90 s and saw an improvement in safety performance.

Client Leadership is essential for any such initiatives to succeed. Not only does the client have to initiate change in the procurement process but the client must be more involved and competent and should expect regular updating of all aspects of construction phase plans. Safe working must be rewarded in order for it to become the norm. This applies at both the organizational and individual level.

\subsection{Employment Practices}

We have only two alternatives, either a comprehensive subcontractor registration system or employment of direct labour.

If we adopt the former approach, it is necessary to devise, implement and maintain a system whereby subcontractors are assessed on their various levels of performance, particularly safety and health, in order to maintain their registration. This is a carrot and stick approach. The other alternative is to encourage major contractors to take on their own direct labour force. This requires consideration by the industry as a whole, led by Development Bureau and the CIC, as to the feasibility of encouraging more direct labour to be employed by Hong Kong contractors. Project Level Issues

There is a whole range of factors that affect health and safety performance at the individual level. These are factors, which directly affect decisions and actions on a dayto-day basis. They include work pressure, team working, risk perception, and fatigue.

\subsection{WORK PRESSURE}

Work pressure leads to negative consequences for individuals. An example of this is the continued use of piece rate systems in the Hong Kong construction industry. This applies pressure to the individual worker either from his own personal goals or from work group pressure. The piece rate payment system is synonymous with subcontracting.

\subsection{TEAM WORKING}

An area which needs attention in Hong Kong is how people discuss, share, communicate and follow-up safety and health information and good practice. Collaborative team working should be encouraged in order to ensure that each and every participant looks after their own and other's safety and health issues. 


\subsection{RISK PERCEPTION}

A recurring theme in discussion of safety and health on Hong Kong construction sites is risk perception, the way in which workers perceive and understand hazards and risks. This is essentially an individual issue. Dealing with a risk can be done by compliance or perception. For repeat risk takers, there should be no tolerance. A three strikes and out policy has been shown to be effective worldwide.

\subsection{FATIGUE}

It is now well known that the physical health and well-being of the ageing workforce in Hong Kong is poor, fatigue is a serious problem on Hong Kong construction sites workers should be empowered to take rests whenever they feel it is necessary and they should also be in a position to refuse to work if they believe the situation is dangerous.

\section{CONCLUSIONS}

This paper has presented a rationale for analysing OHSW in the construction industry. From this analysis a roadmap for OHSW improvement has been developed. The methodology adopted can be used in different cultural contexts but the roadmaps developed will be different dependent on industry maturity.

\section{REFERENCES}

Engineering News Record [Online], 2019, Available from: http://enr.construction.com/business_management/safety_health/2012/0730-london-olympicsconstruction-is-safest-in-recent-times.asp [Accessed 16 October 2019].

Hong Kong Housing Authority [Online], 2019, Available from: https://www.housingauthority.gov.hk/mini-site/site-safety/en/publications/performancestatistics/index.html [Accessed 16 October 2019]

Koh, T.Y., Tuuli, M.M. and Rowlinson, S., 2013. A relational approach to high reliability organising for construction project safety: a conceptual framework. In: Smith, S.D and Ahiaga-Dagbui, D.D (Eds.) Proceedings of the $29^{\text {th }}$ Annual Association of Researchers in Construction Management (ARCOM2013) Conference (pp.369-379). 2-4 September 2013, Reading, UK.

Lingard, H., Pirzadeh, P., Blismas, N., Wakefield, R. and Kleiner, B., 2014. Exploring the link between early constructor involvement in project decision-making and the efficacy of health and safety risk control. Construction Management and Economics, 32(9), pp.918-931.

Lingard, H., Blismas, N., Cooke, T. and Cooper, H., 2009. The model client framework: resources to help Australian Government agencies to promote safe construction. International Journal of Managing Projects in Business, 2(1), pp.131-140.

Metropolis Group, Inc. [Online], 2019, Available from: https://metropolisny.com/2019/02/save-the-datefor-the-2019-build-safe-live-safe-conference/, [Accessed 16 October 2019].

Sherratt, F., 2014. Exploring 'Zero Target' safety programmes in the UK construction industry. Construction Management and Economics, 32(7-8), pp.737-748. 